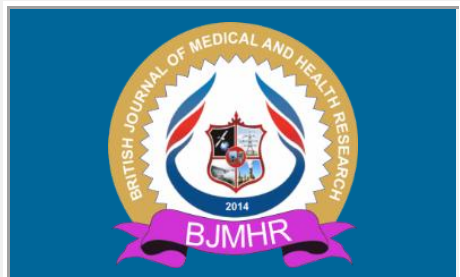

\title{
BJMHR
}

British Journal of Medical and Health Research Journal home page: www.bjmhr.com

\section{Role of D-dimer in Predicting Severity and Mortality of Community-acquired Pneumonia}

\author{
Darina Miteva $^{1 *}$, Yordan Radkov ${ }^{1}$, Vanya Kostadinova ${ }^{1}$ \\ 1. Department of Pulmonology and Allergology, Medical University of Varna, \\ Bulgaria \\ Clinic of Pneumonology and Phthisiatrics, MHAT "St. Marina"- Varna, Bulgaria
}

\section{ABSTRACT}

Coagulation disturbances are one of the markers of systemic inflammation. The aim of the study was to evaluate the role of D-dimer (DD) in predicting severity and mortality of hospitalized patients with community-acquired pneumonia. 143 CAP patients hospitalized in the Clinic of Pneumology and Phthisiatrics at "Saint Marina" University Hospital were retrospectively studied. D-dimer was measured on admission by latex-enhanced immunoturbidimetric method with reference value of $0,232 \mathrm{mg} / \mathrm{L}$. The severity of CAP was determined by PSI, CURB-65 and IDSA/ATS criteria. Patients were on mean age 62.12 \pm 15.54 years, 59.4\% - male. Elevated levels of D-dimer were found in $86.70 \%$ of the patients. The mean DD in non-survivors was significantly higher than in survivors $(2.19 \pm 2.01 \mathrm{mg} / \mathrm{L}$ vs. $1.28 \pm 1.46 \mathrm{mg} / \mathrm{L}, \mathrm{p}<0.05)$. DD increased significantly with increasing the severity group according to PSI, CURB-65 and IDSA/ATS criteria, but the correlation coefficients were weak $(\mathrm{r}=0.25 ; \mathrm{r}=0.23 ; \mathrm{r}=0.22$ resp., $\mathrm{p}<0.001) . \mathrm{DD}>1 \mathrm{mg} / \mathrm{L}$ increased the risk for in-hospital mortality with OR $4.25(1.48-12.14 ; \mathrm{p}<0.01)$.

D-dimer is able to predict severity and outcome of CAP.

Keywords: CAP, D-dimer, severity, mortality

*Corresponding Author Email: dari.miteva@abv.bg

Received 02 September 2018, Accepted 05 October 2018

Please cite this article as: Miteva D et al Role of D-dimer in Predicting Severity and Mortality of Community-acquired Pneumonia. British Journal of Medical and Health Research 2018. 


\section{INTRODUCTION}

Different biomarkers are used as diagnostic and prognostic tools in pneumonia. They can be classified into 3 groups: biomarkers of inflammation, biomarkers of coagulation and biomarkers of infection. To the widely available biomarkers of coagulation belong activated partial thromboplastin time, platelets, fibrinogen and disseminated intravascular coagulation scores. To potential future biomarkers belong protein C, D-dimer (DD), thrombin-antithrombin complexes, prothrombin fragment 1.2 and activated partial thromboplastin time waveform analysis $^{[1]}$. D-dimer is a result from the degradation of fibrin from the activated fibrinolytic system. It is elevated in situations of increased production of fibrin and its subsequent degradation. This is seen in disseminated intravascular coagulation, severe sepsis, thromboembolic events, pregnancy, liver diseases, surgical interventions and trauma ${ }^{[2]}$. Recently data were found that its values are increased in large proportion of patients with CAP. The increase of DD in CAP is associated with several reasons. It may result from the activation of the fibrinolytic system and the degradation of fibrin directly into the alveoli. On the other hand, its levels may increase due to the activation of coagulation processes in the bloodstream, caused by the endotoxins of Gram-negative pathogens. Although the elevation of DD is more prominent in pulmonary embolism it is often elevated in infections such as pneumonia ${ }^{[3,4]}$. More over high levels of DD are associated with increased mortality in patients with infection or sepsis ${ }^{[5]}$. This way DD is not only elevated in pneumonia but it also correlates with the severity and prognosis of the disease.

\section{MATERIAL AND METHOD}

143 CAP patients hospitalized in the Clinic of Pneumology and Phthisiatrics at "Saint Marina" University Hospital in Varna were retrospectively studied. Patients over 18 years old with final diagnosis of CAP were included in the study. The diagnosis was accepted after positive chest image plus at least two of the following: temperature $>38^{\circ} \mathrm{C}$, productive cough, shortness of breath, chest pain, crackles on auscultation. The exclusion criteria were: severe immunosuppression, active malignancy, chronic renal or liver disease, pregnancy, infarction pneumonia, resent thromboembolic events, trauma or surgery. D-dimer was measured on admission by latex-enhanced immunoturbidimetric method with reference value of $0.232 \mathrm{mg} / \mathrm{L}$. The severity of CAP was determined by PSI, CURB-65 and IDSA/ATS criteria. Data were analyzed with statistical program SPSS.20. Comparative analysis, correlation analysis and analysis of risk assessment (OR) were used. Quantitative variables were reported as mean value and standard deviation (mean $\pm \mathrm{SD}$ ) and qualitative variables were reported as a count and 
relative share (\%). $\mathrm{P}<0.05$ was accepted as statistically significant in all comparisons. The study was conducted in accordance with the Institutional Ethical Committee.

\section{RESULTS AND DISCUSSION}

Patients were on mean age 62.12 \pm 15.54 years, 85 (59.4\%) of them were male and 58(40.6\%)female. In the Intensive care unit (ICU) were treated 29 patients $(20.3 \%)$. During the hospital stay 18 patients (12.6\%) died. Elevated levels of DD were found in $86.70 \%$ of the patients. The average value was $1.38 \mathrm{mg} / \mathrm{L} \pm 1.56 \mathrm{mg} / \mathrm{L}$. A significant increase in DD was established in patients with some complications as pleural effusion and acute respiratory failure (ARF), but not in patients with cavitation. Despite the higher value of DD in ICU patients, the difference did not reach significance. Patients with multilobar infiltrates also had higher DD, but the difference was not statistically significant. Data are shown on table 1.

Table.1 Mean value of D-dimer in different conditions

\begin{tabular}{llll}
\hline Indicator & $\begin{array}{l}\text { D-dimer in presence of the } \\
\text { indicator } \mathbf{~ m g} / \mathbf{L}\end{array}$ & $\begin{array}{l}\text { D-dimer in the absence of the } \\
\text { indicator } \mathbf{~ m g / L}\end{array}$ & $\begin{array}{l}\text { P- } \\
\text { value }\end{array}$ \\
\hline $\begin{array}{l}\text { Complications of CAP } \\
\text { Pleural effusion }\end{array}$ & $1.931 \pm 1.897$ & $1.161 \pm 1.354$ & $<0.01$ \\
Cavitation & $2.574 \pm 1.932$ & $1.352 \pm 1.548$ & $>0.05$ \\
ARF & $1.817 \pm 1.829$ & $1.068 \pm 1.258$ & $>0.01$ \\
Multilobar & $1.519 \pm 1.755$ & $1.303 \pm 1.465$ & $>0.05$ \\
infiltrates & & & $>0.05$ \\
Treatment in & $1.83 \pm 1.94$ & $1.27 \pm 1.44$ & \\
ICU & & & \\
\hline
\end{tabular}

We examined the mean value of DD in the severity groups according to PSI, CURB-65 and IDSA/ATS criteria and established that it increased significantly with the increase of the severity of CAP according to the three scales. (Fig.1)
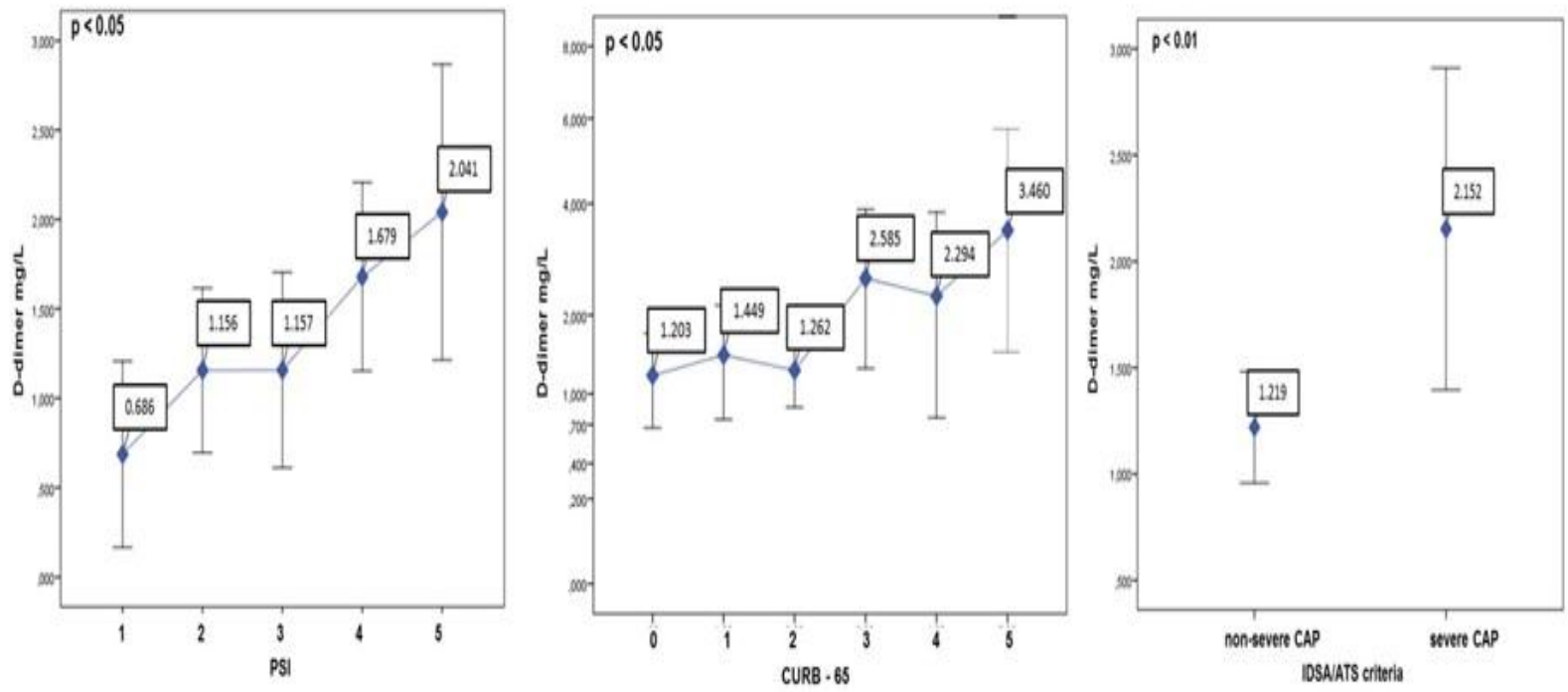

Figure.1 Mean DD in different severity groups according to PSI, CURB-65 and IDSA/ATS criteria 
Although DD increased with increasing the severity group its correlation coefficients with the scales were week (with PSI, CURB-65 and IDSA/ATS criteria they were $r=0.25 ; r=0.23$ and $\mathrm{r}=0.22$ resp.,p<0.001).

We found significantly higher values of DD in deceased patients compared to survivors $(2.19 \pm 2.01 \mathrm{mg} / \mathrm{L}$ vs. $1.28 \pm 1.46 \mathrm{mg} / \mathrm{L}, \mathrm{p}<0.05) . \mathrm{DD}>1 \mathrm{mg} / \mathrm{L}$ increased the risk for in-hospital mortality with OR 4.25 (1.48-12.14; $\mathrm{p}<0.01)$.

Our study found a high incidence of coagulation disorders in CAP as DD was elevated in $86.7 \%$ of the patients. A similar high incidence of increased DD in CAP patients was also found by other authors. Milbrandt established elevated DD in $80.6 \%$ of the patients, and this was observed in both patients with severe sepsis and those who did not develop organ dysfunction [6].

We found also significantly higher D-dimer values in patients with some complications as ARF and pleural effusions. Elevated D-dimer levels in CAP patients with ARF were also reported by other authors ${ }^{[7]}$. However, we have not found a significant difference in DD levels between patients in ICU and conventional ward. Therefore, we consider that DD could not serve as a predictor for the need of intensive care. These results were in contradiction with other authors who found significantly higher DD levels in patients treated in $\operatorname{ICU}^{[8]}$. Chalmers and al. established that low DD values have a negative predictive value for 30-day mortality and need for mechanical ventilation or inotropic support ${ }^{[9]}$. Salluh et al. found that DD is comparable with APACHE II and SOFA indexes as a predictor of in-hospital mortality in patients with severe CAP in the ICU ${ }^{[10]}$.

We also found significant increase of DD in severe CAP according to the three major scales. Such correlation has been established by other authors ${ }^{[7,11,12]}$. According to some of them, the correlation coefficients of DD with the severity scales are strong. For example, according to Zhuang the correlation of DD with PSI is even very strong $(r=0.798, p<0.001)^{[7]}$. Xu Y et al. established correlation coefficients of DD with PSI $r=0.636$ which was even better than those of procalcitonin and C-reactive protein ( $r=0.629$ and $r=0.250$ resp.; $p<0.05^{[11]}$. Our study found weaker correlation coefficients of DD with the main scales.

We found significantly higher DD levels in deceased patients than in survivors, as are the results of other authors ${ }^{[13,14,15]}$. Snijders et al. for instance found significantly higher levels of DD in non-survivors and patients with clinical failure and severe CAP ${ }^{[15]}$. Most likely, significantly elevated levels in non-survivors and in patients with complications may be associated with a more severe systemic inflammatory response in these patients. We found OR of DD $>1 \mathrm{mg} / \mathrm{L}$ for in-hospital mortality $4.25(1.48-12.14 ; \mathrm{p}<0.01)$. Therefore we assume that patients with $\mathrm{DD}>1 \mathrm{mg} / \mathrm{L}$ should be considered as having an increased risk of mortality. They 
need increased attention by the physicians and more aggressive treatment in order to improve the prognosis of the disease.

\section{CONCLUSION}

D-dimer is elevated in most of the patients with CAP. It can be considered a reliable prognostic marker, identifying patients with increased risk of severe disease and mortality.

\section{REFERENCES}

1. Christ-Crain M, Opal SM. Clinical review: the role of biomarkers in the diagnosis and management of community-acquired pneumonia. Crit Care. 2010;14(1):203. doi: $10.1186 / \mathrm{cc} 8155$

2. Wada H, Sakuragawa N, Mori Y, Takagi M, Nakasaki T, Shimura M, et al. Hemostatic molecular markers before the onset of disseminated intravascular coagulation. Am $\mathbf{J}$ Hematol. 1999;60(4):273-8

3. Karalezli A, Hasanoğlu CH, Kaya S, Babaoğlu E, Acikgoz ZC, Kanbay A, Oztuna D. Cut-off value of D-dimer in pulmonary thromboembolism and pneumonia. Turk J Med Sci 2009; 39 (5): 687-692. doi:10.3906/sag-0903-9

4. Paparoupa M, Spineli L, Framke T, Ho H, Schuppert F, Gillissen A. Pulmonary Embolism in Pneumonia: Still a Diagnostic Challenge? Results of a Case-Control Study in 100 Patients. Disease Markers. 2016, Article ID 8682506, 8 pages. http://dx.doi.org/10.1155/2016/8682506

5. Rodelo JR, De la Rosa G, Valencia ML, Ospina S, Arango CM, Gómez CI, et al. Ddimer is a significant prognostic factor in patients with suspected infection and sepsis. Am J Emerg Med. 2012;30(9):1991-9. doi: 10.1016/j.ajem.2012.04.033.

6. Milbrandt EB, Reade MC, Lee M, Shook SL, Angus DC, Kong L, Carter M, Yealy DM, Kellum JA; GenIMS Investigators. Prevalence and significance of coagulation abnormalities in community-acquired pneumonia. Mol Med. 2009;15(11-12): 438-45

7. Zhuang Q, Zeng Y, Shi Y. Coagulopathy correlates with outcomes in patients with community- acquired pneumonia. Zhonghua Jie He He Hu Xi Za Zhi. 2014;37(6):40610

8. Arslan S, Ugurlu S, Bulut G, Akkurt I. The association between plasma D-dimer levels and community-acquired pneumonia. Clinics (Sao Paulo). 2010;65(6):593-7.

9. Chalmers JD, Singanayagam A, Scally C, Hill AT. Admission d-dimer can identify low-risk patients with CAP. Ann Emerg Med 2009; 53 (5): 633 - 638

10. Salluh JI, Rabello LS, Rosolem MM, Soares M, Bozza FA, Verdeal JC, et al. The impact of coagulation parameters on the outcomes of patients with severe community- 
acquired pneumonia requiring intensive care unit admission. $J$ Crit Care. 2011;26(5):496-501

11. Xu Y, Zhang Y, Jiang F, Zheng H, Zhang Y, et al. Comparison of relevant indicators of coagulation and fibrinolysis in patients with varying severity of community-acquired pneumonia. Zhonghua Yi Xue Za Zhi. 2015;95(24):1925-9

12. Güneysel O, Pirmit S, Karakurt S. Plasma d-dimer levels increase with the severity of community acquired pneumonia. Tuberk Toraks. 2004;52(4):341-7.

13. Querol-Ribelles JM, Tenias JM, Grau E, Querol-Borras JM, Climent JL, Gomez E, Martinez I. Plasma d-dimer levels correlate with outcomes in patients with communityacquired pneumonia. Chest. 2004; 126(4): 1087-92. doi: 10.1378/chest.126.4.1087.

14. Shilon Y, Shitrit AB, Rudensky B, et al. A rapid quantitative D-dimer assay at admission correlates with the severity of community acquired pneumonia. Blood Coagul Fibrinolysis. 2003;14(8):745-8

15. Snijders D, Schoorl M, Schoorl M, Bartels PC, van der Werf TS, Boersma WG. Ddimer levels in assessing severity and clinical outcome in patients with communityacquired pneumonia. A secondary analysis of a randomized clinical trial. Eur J Internal Medicine. 2012, 23 (5), p. 436-441. DOI:10.1016/j.ejim.2011.10.019

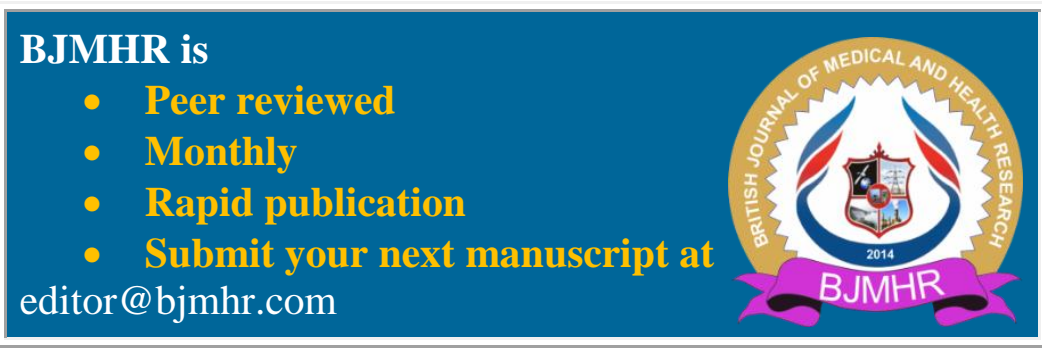

